\title{
Opinion
}

\section{Sir Charles Bell was not affected by facial paralysis himself !}

Despite our recent commentary on the article by Resende and Weber ${ }^{1}$, the authors still seem to believe that Sir Charles Bell (1774-1842) himself was affected by facial paralysis ${ }^{2}$. They came to this erroneous conclusion from a paper by Jongkees ${ }^{3}$ and by "neurological examination of the photograph of Sir Charles Bell” (Fig 1).

However, had they taken the effort to check Jongkees' German translation with the original English text in Bell's publication ${ }^{4}$ the authors would most probably have come to our conclusion that this case report had nothing to do with the clinical history of Sir Charles Bell himself, but that it was a self-observation by Roux of Paris, who indeed did suffer facial paralysis (Fig 2).

To our knowledge there is no original photograph of Bell available. What the authors believe to be a photograph of Bell is in fact an engraving made by J. Thompson (probably James Thompson (1788-1850)). The engraving was published in Thomas Joseph Pettigrew's (17911865) 'Biographical memoirs of the most celebrated physicians, surgeons, etc. etc. ${ }^{5}$, and is part of a biography of Charles Bell, in which no evidence can be found of Bell having had facial paralysis. Thompson had made this engraving after a painting of Bell by John Ballentyne (18151897), which makes it an even less objective depiction of Sir Charles Bell. This is clearly illustrated by differences between Thompson's engraving and the painting of Bell by Dorofield Hardy (1882-1920) (Fig 3), who also used Ballentyne's painting as an example ${ }^{6}$.

In general an artwork is less accurate than a photograph as it is more subject to the personal interpretations, preferences and choices of the artist. Moreover, one has to be careful to conclude that a piece of art such as an engraving, depicts facial paralysis, as it is static in the facial expression and the course of the paralysis. Studying Thompson's engraving and Hardy's painting with the same 'biased' attitude as the authors do, we can state that there is no nasal deviation and a perfectly normal nasolabial fold, which plead against a facial paralysis.

Therefore, we think that the authors must provide other and better evidence if they still believe that Sir Charles Bell had facial paralysis himself. Otherwise, we hope that this historical error has now been rectified.

\section{REFERENCES}

1. Korteweg SFS, Van de Graaf RC, Werker PMN. About the right facial palsy of Charles Bell. Was Sir Charles Bell himself really affected by facial paralysis?

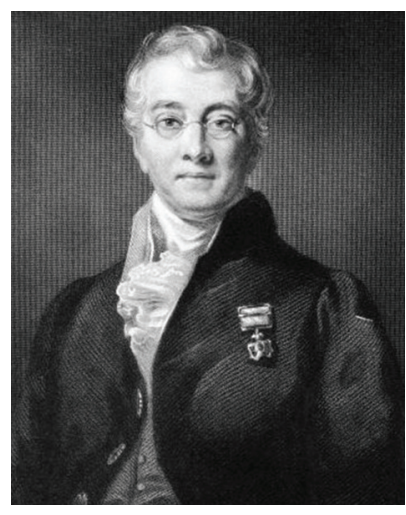

Fig 1. Engraving of Sir Charles Bell, made by J. Thompson (probably James Thompson (1788-1850), on which the autors based their diagnosis of right facial paralysis.

XVII. Case of Paralysis of the Face,

In M. le Professeur Roux, of Paris ; communicated by himself to M. Descot.

“ I have for many years been subject to rheumatism, which has most commonly been seated in the loins. In the month of October, 1821, I was attacked with paralysis of the right side of my face.

Fig 2. A copy from Bell's original work in which is clearly stated that the case of paralysis of the face concerns Roux of Paris.

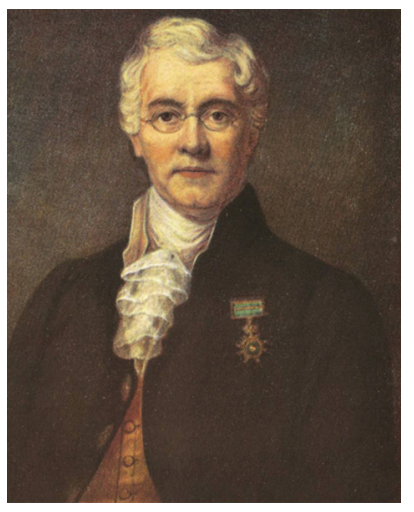

Fig 3. Painting of Sir Charles Bell by Dorofield Hardy (1882-1920) Like the engraving by Thomson Hardy used Ballentyne's painting as an example. No signs of facial paralysis are seen. There are normal wrinkles on the forehead; both eyebrows are normal and symmetric; the palpebral fissurae are equal; there are symmetric mouth angles; the nasolabial folds are equal and there are no signs of nose deviation.

Comment on "Peripheral facial palsy in the past: contributions from Avicenna, Nicolaus Friedreich and Charles Bell". Arq Neuropsiquiatr 2009;67:783.

2. Resende LAL, Weber SAT. The authors' reply on "About the right facial palsy of Charles Bell". Arq Neuropsiquiatr 2009;67:783-784.

3. Jongkees LBW. Bemerkungen zur Geschichte der Fazialischirurgie. HNO 1979;27:325-333

4. Bell C. Case of paralysis of the face. In M. le Professeur Roux, of Paris; communicated by himself to M. Descot. Appendix to the papers on the nerves. London: Longman, Hurst, Rees, Orme, Brown \& Green 1827:68-72. 
5. Pettigrew TJ. Biographical memoirs of the most celebrated physicians, surgeons, etc. etc. London: Whittaker and Co., Ave-Maria Lane 1839.

6. Gordon Taylor G, Wall EW. Sir Charles Bell, his life and times. Edinburgh and London: E\&S Livingstone Ltd, 1958.

\author{
Korteweg SFS, MD \\ Van de Graaf RC, MD \\ Werker PMN, MD, PhD \\ Department of Plastic Surgery, \\ University Medical Center Groningen, The Netherlands \\ P.O. Box 30.001 - NL-9700 RB Groningen \\ E-mail:s.f.s.korteweg@plchir.umcg.nl
}

\section{THE AUTHORS' REPPLY}

The Netherlands are really a country of contrasts. The South is predominantly industrialized, in the North predominates agriculture. The South is catholic, the North Calvinist. The South is more populous, the North less. There is carnival at the South, but not at the North. In the South live more immigrants, in the North less. In Amsterdam, Dutch language is predominant, in the North dialects are more common. Professor L.B.W. Jongkees lived and worked in Amsterdam, and is dead. Korteweg lives and works in Gröningen, and probably is young. Professor Jongkees worked on and studied the interior of the cranium, as an otolaryngologist; Korteweg works on the exterior of the cranium, as a plastic surgeon. Professor Jongkees published over 400 papers ${ }^{1}$, and was Editor-inChief of the Dutch Journal of Medicine (1971-1982) (Fig 1 ). Korteweg has 1 (one) published paper, in this periodic, where he affirms that Jongkees "introduced an error": the right facial paralysis of Charles Bell.

By Professor Jongkees, by all professors of the world, and in the internet, Sir Charles Bell is presented on a black-and-white good quality portrait. This portrait was shown in our published paper about the history of facial palsy $^{2}$. Korteweg showed an almost unknown colored bad quality image.

Professor Jongkees was probably modest and simple, as we can see in the letter to the first author (Resende LAL), written in 1983, when Resende was a simple and unknown Medical Resident of South America (Fig 2). Professor Jonkees wrote "... I am sorry that my typing is not very good but I retired some time ago and now I have no secretary anymore". Based on this analysis, we may conclude that we are in front of a new Dutch baroque problem: Korteweg versus Professor Jongkees. To solve this new Dutch baroque problem, we suggest the help of an old Dutch baroque Professor: Rembrandt Harmenszoon van Rijn (Fig $3)$. In this self-portrait of $1629-1630^{3}$, Rembrandt probably had a "clinical problem" on his right face. Can Korteweg et al. solve this enigma? What may be the diagnosis? We think that this solution would help them to solve the conundrum of the clinical problem presented in the right hand side face of Sir Charles Bell portrait (we carefully selected one Rembrandt's painting with right hand face problem to facilitate the clinical exercise of Korteweg et al.).

If necessary, they may access another paper where Tizian and Tintoretto presented people with similar "enigmatic" clinical problems on the right hand side face ( $\mathrm{Re}-$ sende LAL et al., 2010). We carefully selected only right hand face presentations to facilitate the clinical exercise of Korteweg et al.

\section{REFERENCES}

1. Van't Hof SE. Leonard Barend Willem Jongkees, editor-in-chief of the Dutch Journal of Medicine (1971-1982). Ned Tijdschr Geneeskd. 2007;151: 2913-2915.

2. Resende LA, Weber SAT. Peripheral facial palsy in history: the contributions of Avicenna, Nicolaus Friedreich and Charles Bell. Arq Neuropsiquia$\operatorname{tr}$ 2008;66:765-769.

3. Mannering D. A arte de Rembrandt. Rio de Janeiro: Livro Técnico, 198131.

\author{
Resende LAL* \\ Weber SAT* \\ Services of Neurology* and Othology* \\ Botucatu School of Medicine \\ 18618-000 Botucatu SP - Brasil \\ E-mail: luanlire@hotmail.com
}

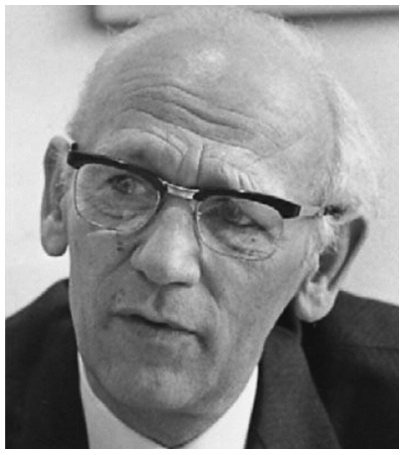

Fig 1. Professor Leonard Barend Willem Jongkees (1912-2002), editor-in-chief of the Dutch Journal of Medicine (1971-1982).

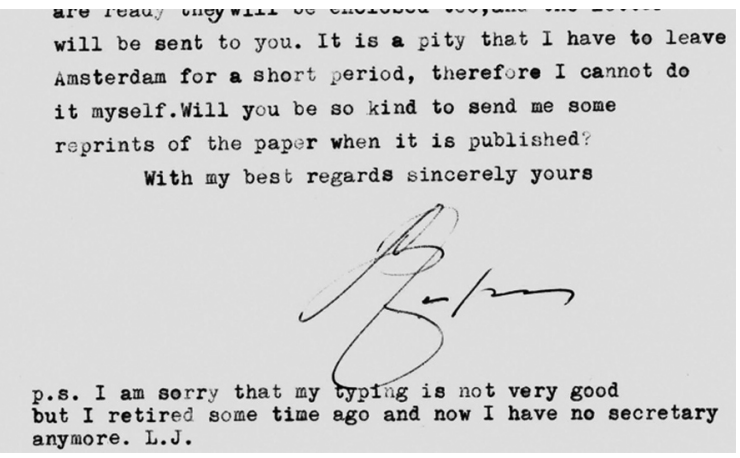

Fig 2. Part of the letter from Yongkees sent to the first author (Resende LA) in 1983.

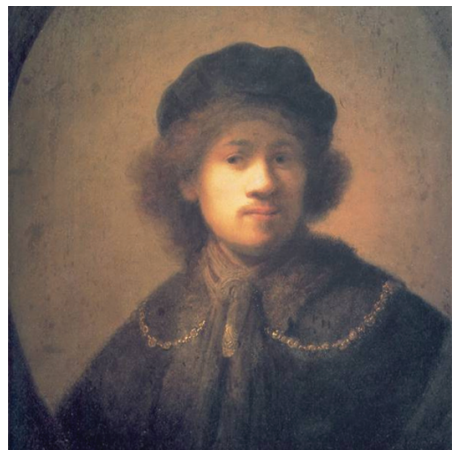

Fig 3. Rembrandt's self-portrait (1629-1630). We can see facial asymmetry (like Charles Bell portrait). How is the probable diagnosis? 